IRA-International Journal of Technology \& Engineering

ISSN 2455-4480; Vol.04, Issue 01 (2016)

Institute of Research Advances

http://research-advances.org/index.php/IRAJTE

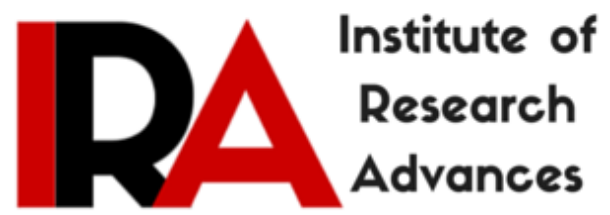

\title{
The Effect of a Single and Combined Slot Generated At the Upper and Lower Part of the Rectangular Patch Antenna Performances
}

\author{
${ }^{1}$ Adnan Affandi , ${ }^{2}$ Navin Kasim, ${ }^{3}$ Talal Hamdan Hamad Althebiani \\ 1,2,3 Electrical and Computer Engineering Department, \\ King Abdul Aziz University, P.O. BOX: 80204, Jeddah 2158.
}

DOI: http://dx.doi.org/10.21013/jte.v4.n1.p3

\section{How to cite this paper:}

Affandi, A., Kasim, N., \& Althebiani, T. (2016). The Effect of a Single and Combined Slot Generated At the Upper and Lower Part of the Rectangular Patch Antenna Performances. IRA-International Journal of Technology \& Engineering (ISSN 24554480), 4(1). doi:http://dx.doi.org/10.21013/jte.v4.n1.p3

(C) Institute of Research Advances (cc) EY-NC

This works is licensed under a Creative Commons Attribution-Non Commercial 4.0 International License subject to proper citation to the publication source of the work.

Disclaimer: The scholarly papers as reviewed and published by the Institute of Research Advances (IRA) are the views and opinions of their respective authors and are not the views or opinions of the IRA. The IRA disclaims of any harm or loss caused due to the published content to any party. 


\begin{abstract}
The paper investigates the effect of the slot made on the radiating plane (top) and ground plane individually and their effect when made on both the surfaces on the antenna performance. The paper further investigates effect of the slot on gain, frequency and radiation pattern made at different angles more specifically at angles of $0^{\circ}, 45^{\circ}$ and $90^{\circ}$ to the antenna feed line.

The antenna has been designed using advanced system design (ADS).
\end{abstract}

Keywords: Slot, Antenna, Radiation Pattern, Frequency, Microstrip,ADS

\title{
Introduction
}

The paper investigates the effect of the slot on the rectangular microstrip patch in three parts. The first part mainly investigates the antenna performance due to the effect of single slot generated on the patch antenna radiating side. Part two studies the effect of the generated slot on the ground plane investigates while the third part investigates the effect due to the slot on both the planes. These performances covers gain, bandwidth ,radiation made at different angles more specifically at $0^{\circ}, 45^{\circ}$ and $90^{\circ}$ to the antenna feed line.

\section{The Effect of The Top Opened Slot on the Rectangular Patch antenna Performance}

Investigation into the effect of the opened rectangular slot with different angles at $0^{\circ}, 45^{\circ}$ and $90^{\circ}$ to the antenna feed line on the antenna performance as illustrate in the following sections.

\subsection{Single Rectangular Patch Antenna with Angle $0^{\circ}$ Slot (Parallel to antenna feed line)}

The layout of the rectangular patch antenna with angle $0^{\circ}$ slot (Parallel to antenna feed

line) is shown in figure 1.1, While its simulated return loss as a function of frequency is shown in figure 1.2 .

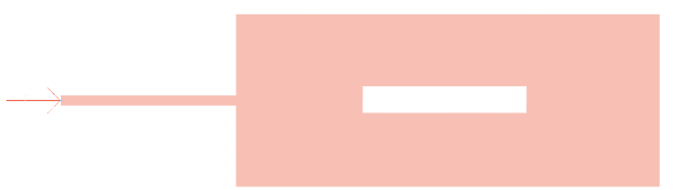

Figure 1.1 Rectangular patch antenna with angle $0^{\circ}$ slot

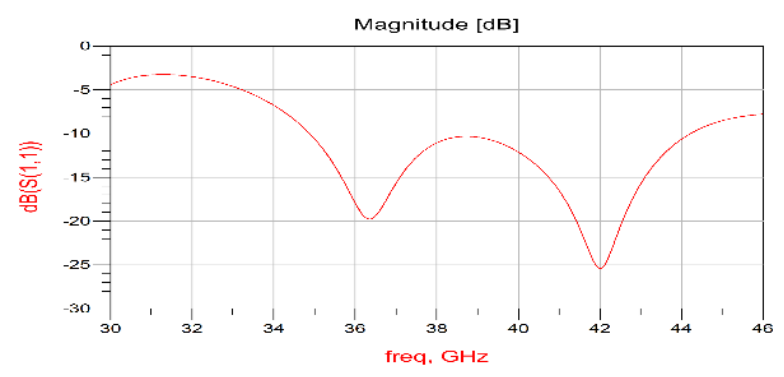

Figure 1.2 Frequency Response of the rectangular patch antenna with angle $0^{\circ}$ slot

It is clear from figure 1.2 that the frequency response of the antenna with the opened slot on the top conductor parallel to feed line provides broadband with dual operations. This antenna operates at $42 \mathrm{GHz}$ with a return loss of -25.41 and gain of $6.08 \mathrm{~dB}$.Also its clear figure 1.3 and table 1 the $3 \mathrm{D}$ radiation pattern of the antenna and its computed parameters respectively. 


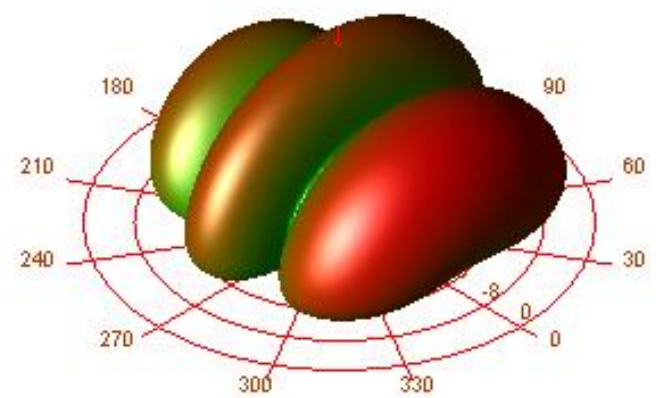

Figure 1.3 3D Radiation pattern of rectangular antenna with angle $0^{\circ}$ slot

TABLE 1 Antenna Parameters of Rectangular Antenna with Angle $0^{\circ}$ Slot

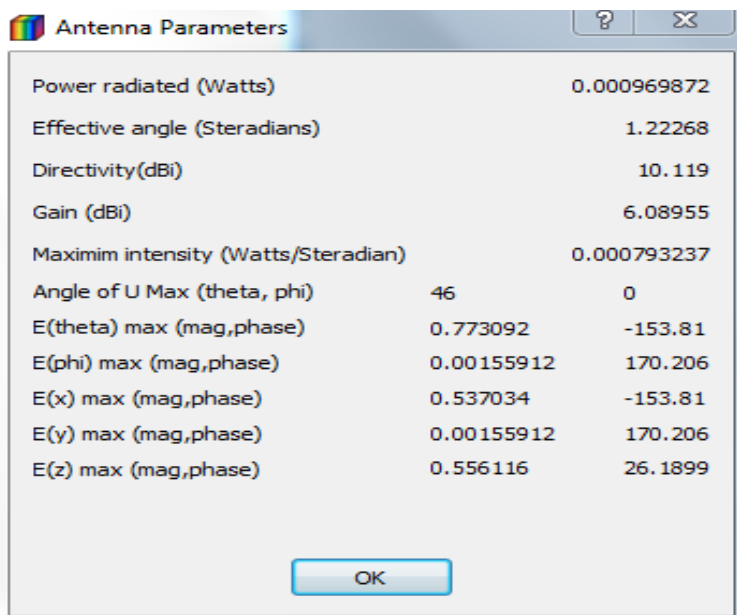

\subsection{Single Rectangular Patch Antenna with Angle $45^{\circ}$ Slot}

The layout of the rectangular patch antenna with angle $45^{\circ}$ slot on the antenna feed line is shown in figure 1.2.1, while its simulated return loss as a function of frequency is shown in figure 1.2.2. Figure 1.2.3 and table 2 show the $3 \mathrm{D}$ radiation pattern and the antenna simulated parameters respectively.

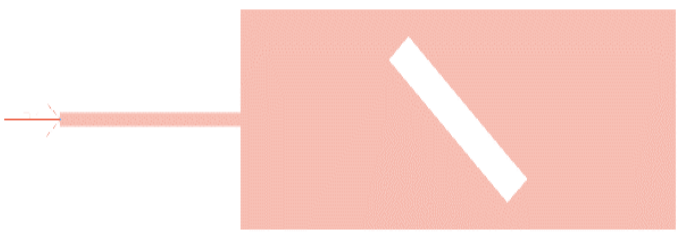

Figure 1.2.1 Rectangular patch antenna with angle $45^{\circ}$ slot 


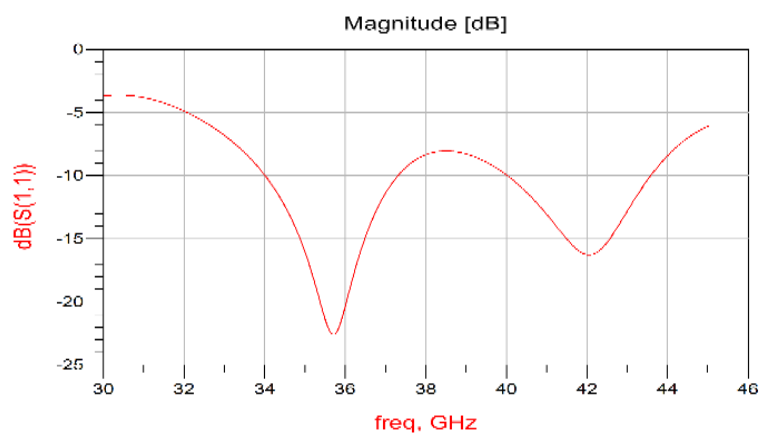

Figure 1.2.2 Frequency Response of the rectangular patch antenna with angle $45^{\circ}$ slot

It is obvious from figure 1.2.2, the antenna operates at $35.74 \mathrm{GHz}$ and $42 \mathrm{GHz}$ (Dual frequency) with return less of $-22.5 \mathrm{~dB}$ and -16.26 respectively. The calculated gain were $5.37 \mathrm{~dB}$ and $4.2 \mathrm{~dB}$ respectively .This antenna is suitable for Millimeter Wave Wireless Communication.

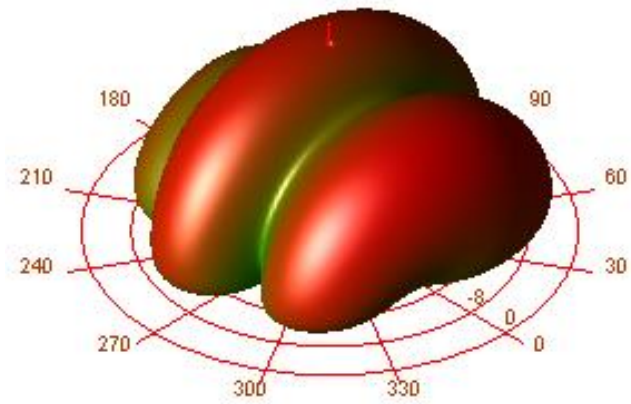

Figure 1.2.3 3D Radiation pattern of rectangular patch antenna with angle $45^{\circ}$ slot

TABLE 2 Antenna Parameters of Rectangular Patch Antenna with Angle $45^{\circ}$ Slot

\begin{tabular}{|c|c|c|}
\hline 11] Antenna Parameters & & 8) $\mathbb{X}$ \\
\hline Power radiated (Watts) & & 0.00154792 \\
\hline Effective angle (Steradians) & & 1.70975 \\
\hline Directivity(dBi) & & 8.66277 \\
\hline Gain (dBi) & & 5.37104 \\
\hline Maximim intensity (Watts/Steradian) & & 0.000905352 \\
\hline Angle of $\cup$ Max (theta, phi) & 44 & 356 \\
\hline $\mathrm{E}$ (theta) max (mag,phase) & 0.809255 & -143.222 \\
\hline E(phi) max (mag,phase) & 0.165084 & 96.7906 \\
\hline$E(x) \max$ (mag,phase) & 0.575042 & -144.216 \\
\hline$E(y) \max$ (mag,phase) & 0.188292 & 86.0249 \\
\hline $\mathrm{E}(\mathrm{z}) \max$ (mag,phase) & 0.562156 & 36.7779 \\
\hline OK & & \\
\hline
\end{tabular}




\subsection{Single Rectangular Patch Antenna with Angle 90 ${ }^{\circ}$ Slot}

The layout of the rectangular patch antenna with angle $90^{\circ}$ slot on the antenna feed line is shown in figure 1.3.1, While its simulated return loss as a function of frequency is shown in figure 1.3.2. It is clear from the frequency response that a dual bandwidth of $2.6 \mathrm{GHz}$ and $1.6 \mathrm{GHz}$ are obtained at frequency of 34.9 $\mathrm{GHz}$ and $42.8 \mathrm{GHz}$ respectively.

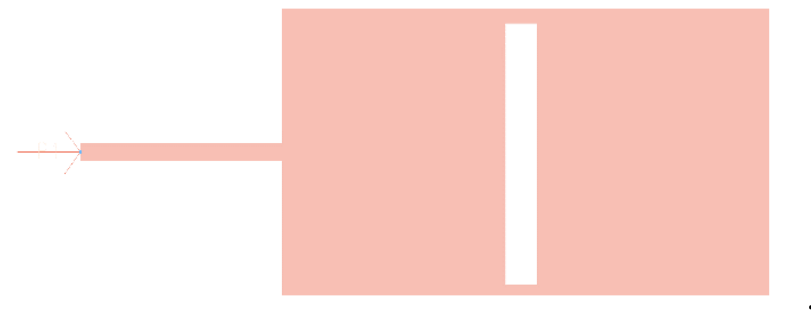

Figure 1.3.1 Rectangular patch antenna with angle $90^{\circ}$ slot

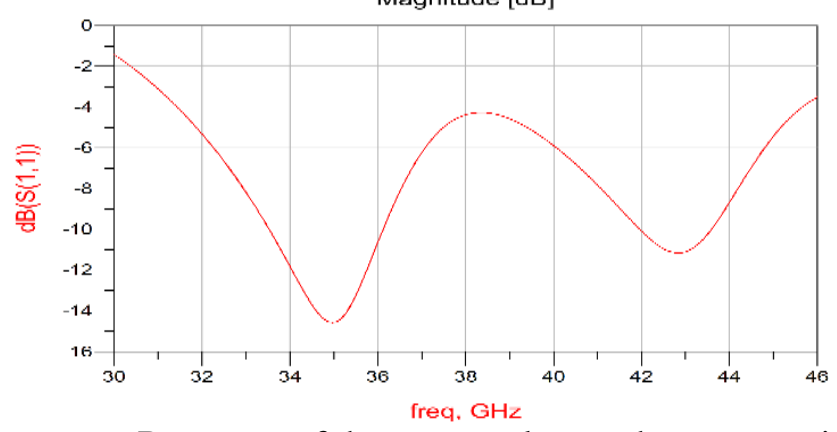

Figure 1.3.2 Frequency Response of the rectangular patch antenna with angle $90^{\circ}$ slot

It is observed from figure 1.3.2, the antenna performance such as bandwidth, return loss and gain are decrease if the slot was made $90^{\circ}$ angle on the antenna feed line.

Figure 1.3.3 shows the $3 \mathrm{D}$ radiation pattern which is just satisfactory, while table 3.5 represents the simulated antenna parameters .a gain of $3.84 \mathrm{~dB}$ is achieved.

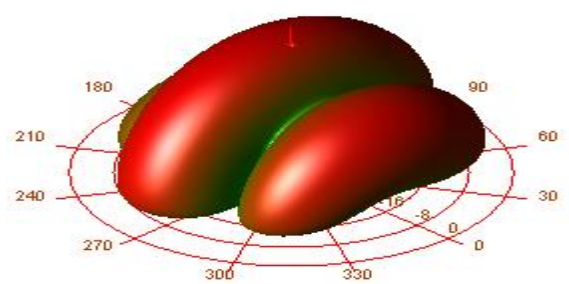

Figure 1.3.3 3D Radiation pattern of rectangular antenna with angle $90^{\circ}$ slot 
TABLE 3 Antenna Parameters of Rectangular Antenna with Angle 90 Slot

\begin{tabular}{|c|c|c|}
\hline 11] Antenna Parameters & & ह 23 \\
\hline Power radiated (Watts) & & 0.00090653 \\
\hline Effective angle (Steradians) & & 2.03182 \\
\hline Directivity(dBi) & & 7.91325 \\
\hline Gain (dBi) & & 3.84444 \\
\hline Maximim intensity (Watts/Steradian) & & 0.000446167 \\
\hline Angle of $\cup$ Max (theta, phi) & 14 & 230 \\
\hline $\mathrm{E}$ (theta) max (mag,phase) & 0.38302 & -144.534 \\
\hline E(phi) max (mag,phase) & 0.435276 & 29.1516 \\
\hline$E(x) \max$ (mag,phase) & 0.571483 & 31.7865 \\
\hline$E(y) \max ($ mag,phase) & 0.0314705 & 113.356 \\
\hline $\mathrm{E}(\mathrm{z}) \max$ (mag,phase) & 0.0926609 & 35.4655 \\
\hline OK & & \\
\hline
\end{tabular}

TABLE 4 Comparison of Performance Parameters of the Rectangular Patch Antenna Geometries

\begin{tabular}{|c|c|c|c|c|c|c|}
\hline $\begin{array}{c}\text { Rectangular patch } \\
\text { antenna }\end{array}$ & $\begin{array}{c}\text { Frequen } \\
\text { cy GHz }\end{array}$ & $\begin{array}{c}\text { (S11<-10dB) } \\
\text { BW GHz }\end{array}$ & $\begin{array}{c}\text { Return } \\
\text { Loss (dB) }\end{array}$ & $\begin{array}{c}\text { Gain } \\
\text { dB }\end{array}$ & $\begin{array}{c}\text { Directivi } \\
\text { ty dB }\end{array}$ & $\begin{array}{c}\text { Remar } \\
\mathbf{k}\end{array}$ \\
\hline without slot & 42 & 9.44 & -27.38 & 5.93 & 10.63 & \\
\hline with angle 0 ${ }^{\circ}$ slot & 42 & 9.33 & -25.41 & 6.09 & 10.12 & \\
\hline with angle 45 $5^{\circ}$ slot & 42.11 & 7.55 & -22.5 & 5.37 & 8.66 & $\begin{array}{c}\text { Dual } \\
\text { Bandwidt } \\
\text { h }\end{array}$ \\
\hline with angle 90 $0^{\circ}$ slot & 42.83 & 4.2 & -14.57 & 3.84 & 7.9 & $\begin{array}{c}\text { Dual } \\
\text { Bandwidt } \\
\text { h }\end{array}$ \\
\hline
\end{tabular}

Table 4 summarizes the performance of rectangular patch antenna with opened slot of different angles at $0^{\circ}, 45^{\circ}$ and $90^{\circ}$ on the antenna feed line. From above summary table 3.6, someone can observe clearly the slot effects on antenna performance. the rectangular patch antenna with angle $0^{\circ}$ slot on the antenna feed line has the best performance more than others. However, The return loss, bandwidth, antenna gain and directivity with slot angle position are gradually decreasing and frequency shift has been occurred too. Furthermore, Dual operation in $45^{\circ}$ and $90^{\circ}$ slot angle which can be utilized in different frequency bands applications such as in satellite communication and millimeter wave communications

\section{The Effect of the Rectangular Slot in the Ground Plane on the Rectangular Patch Antenna Performance}

Circular Polarized Rectangular Patch Antenna with slot has been designed and simulated as shown in next figures to studying the effect of the rectangular slot with different angles at $0^{\circ}, 45^{\circ}$ and $90^{\circ}$ to the antenna feed line on the antenna performance. The single patch antenna is selected according to the required specification with the best performance which satisfies certain application is given in table 5 . 
TABLE 5. Single Rectangular Patch Antenna Design Specifications

\begin{tabular}{|c|c|}
\hline Frequency & $36.5 \mathrm{GHz}$ \\
\hline Substrate & RO4003C \\
\hline Dielectric Constant $\varepsilon r$ & 3.38 \\
\hline Substrate Height & $1.524 \mathrm{~mm}$ \\
\hline
\end{tabular}

\subsection{Rectangular Patch Antenna with $0{ }^{\circ}$ Slot on the Ground Plane}

The layout of the rectangular patch antenna with $0^{\circ}$ slot on the ground plane is shown in figure 2.1.1 with table 5 specification, while its simulated return loss as a function of frequency is shown in figure 2.1.2.

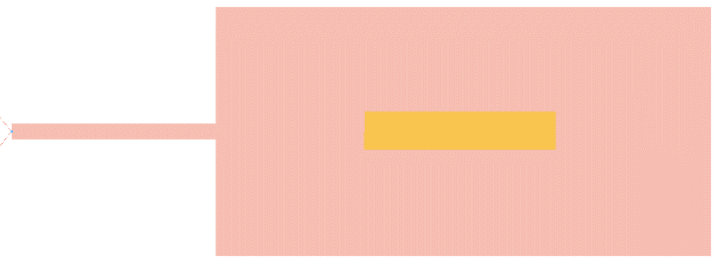

Figure 2.1.1 Rectangular patch antenna with rectangular slot made on the ground plane with $0^{\circ}$ to the antenna feed line

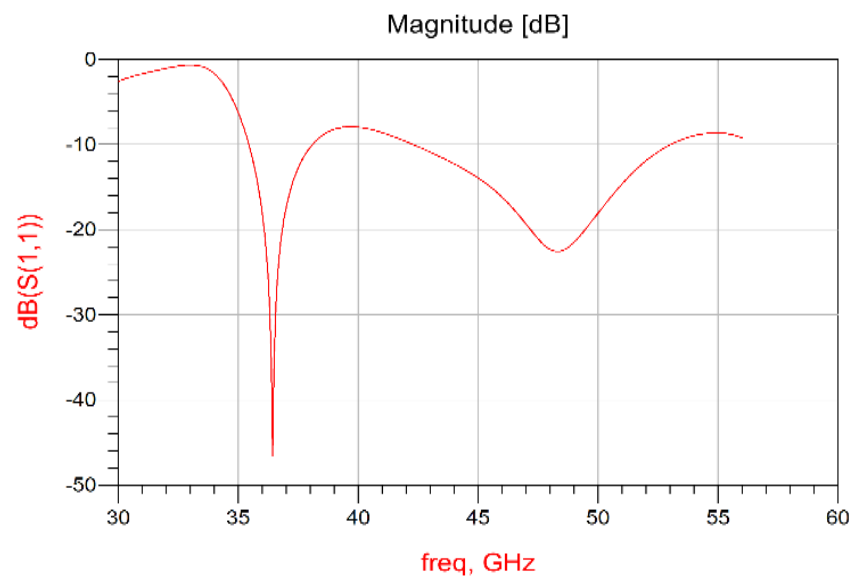

Figure 2.1.2 The return loss of the rectangular patch antenna with rectangular slot made on the ground plane with $0^{\circ}$ to the antenna feed line

It is observed from figure 2.1.2 that the rectangular antenna operates at dual frequency $36.5 \mathrm{GHz}$ and 48 $\mathrm{GHz}$ with return less of $-46 \mathrm{~dB}$ and $-22 \mathrm{~dB}$ respectively. High gain of $9.3 \mathrm{~dB}$ and $7.5 \mathrm{~dB}$ are obtained see table 6 .The polarization of this proposed antenna is found to be linear due to that the slot on the ground plane made parallel to the feed line. This shows that there is no effect on the polarization of the antenna see figure 2.1.3. The major applications for such extremely high frequency range for this kind of antenna is Astronomy and Remote Sensing application. 


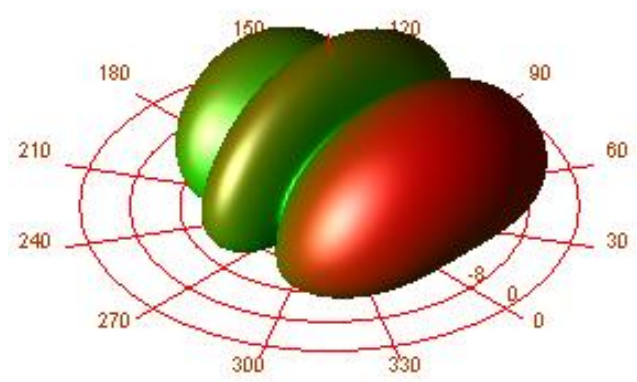

Figure 2.1.3 3D Radiation pattern of the rectangular patch antenna with rectangular slot made on the ground plane with $0^{\circ}$ to the antenna feed line

TABLE 6 The Rectangular Patch Antenna Parameters with Rectangular Slot Made on the Ground Plane with $0^{\circ}$ to the Antenna Feed Line

\begin{tabular}{|c|c|c|}
\hline 11] Antenna Parameters & & $\Sigma 3$ \\
\hline \multicolumn{2}{|l|}{ Power radiated (Watts) } & 0.00179454 \\
\hline \multicolumn{2}{|l|}{ Effective angle (Steradians) } & 0.914645 \\
\hline \multicolumn{2}{|l|}{ Directivity (dBi) } & 11.3796 \\
\hline \multicolumn{2}{|l|}{ Gain (dBi) } & 9.34637 \\
\hline \multicolumn{2}{|c|}{ Maximim intensity (Watts/Steradian) } & 0.00196201 \\
\hline Angle of $U$ Max (theta, phi) & 50 & 0 \\
\hline$E$ (theta) max (mag,phase) & 1.21585 & 174.304 \\
\hline $\mathrm{E}$ (phi) max (mag,phase) & 0.000449654 & 16.3284 \\
\hline$E(x) \max$ (mag,phase) & 0.781536 & 174.304 \\
\hline$E(y) \max ($ mag,phase) & 0.000449654 & 16.3284 \\
\hline \multirow[t]{2}{*}{$E(z) \max$ (mag,phase) } & 0.931398 & -5.69562 \\
\hline & & \\
\hline
\end{tabular}

\subsection{Rectangular Patch Antenna with $45^{\circ}$ Slot on the Ground Plane}

The layout of the rectangular patch antenna with $45^{\circ}$ slot on the ground plane is shown in figure 2.2 .1 with table 5 specification, While its simulated return loss as a function of frequency is shown in figure 2.2.2.

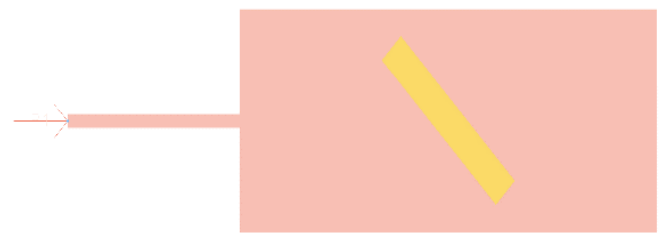

Figure 2.2.1. Rectangular patch antenna with rectangular slot made on the ground plane with $45^{\circ}$ to the antenna feed line 


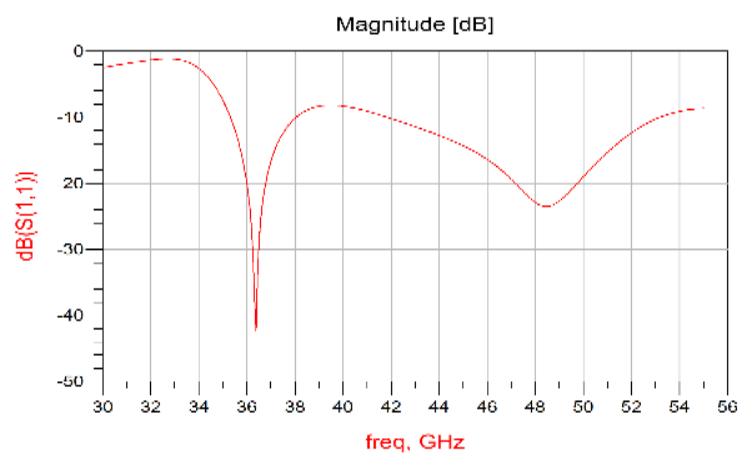

Figure 2.2.2. The return loss of the rectangular patch antenna with rectangular slot made on the ground plane with $45^{\circ}$ to the antenna feed line

Figure 2.2.2 shows the return loss of this proposed antenna with the rectangular slot made in the ground plane at $45^{\circ}$ on the feed line of the antenna. It is clear from this frequency response that this proposed antenna has dual bandwidth at 36.5 and $48.5 \mathrm{GHz}$ respectively. This antenna provides a wide bandwidth of $11.3 \mathrm{GHz}$ at $48.5 \mathrm{GHz}$, while offers a bandwidth of $2.7 \mathrm{GHz}$ at $36.4 \mathrm{GHz}$. The major applications for such extremely high frequency range for this kind of antenna is Astronomy and Remote Sensing application.

Figure 2.2.3. shows the 3D circular polarized radiation pattern. It is obvious from the radiation pattern that this proposed antenna provide circular polarized operation, but unfortunately the lower part of radiation is extremely narrow, while the top part is wide. Again of 9.51 and $7.6 \mathrm{~dB}$ are achieved respectively see table 7 .

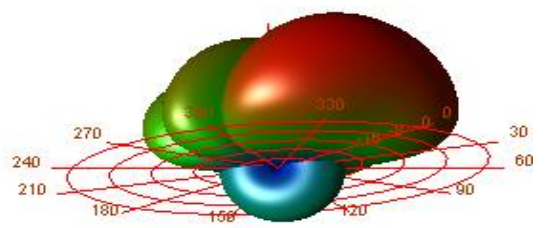

Figure 2.2.3. 3D Radiation pattern of the rectangular patch antenna with rectangular slot made on the ground plane with $45^{\circ}$ to the antenna feed line

TABLE 7. The Rectangular Patch Antenna Parameters with Rectangular Slot Made on the Ground Plane with $45^{\circ}$ to the Antenna Feed Line

\begin{tabular}{|c|c|c|}
\hline Antenna Parameters & & $\Sigma 3$ \\
\hline Power radiated (Watts) & & 0.00177073 \\
\hline Effective angle (Steradians) & & 0.948588 \\
\hline Directivity (dBi) & & 11.2213 \\
\hline Gain (dBi) & & 9.515 \\
\hline Maximim intensity (Watts/Steradian) & & 0.0018667 \\
\hline Angle of $U$ Max (theta, phi) & 49 & 0 \\
\hline E(theta) max (mag,phase) & 1.18579 & 176.042 \\
\hline$E$ (phi) max (mag,phase) & 0.0197371 & -41.2015 \\
\hline$E(x) \max ($ mag,phase) & 0.777948 & 176.042 \\
\hline$E(y) \max ($ mag,phase) & 0.0197371 & -41.2015 \\
\hline$E(z) \max ($ mag,phase) & 0.894927 & -3.95845 \\
\hline OK & & \\
\hline
\end{tabular}




\subsection{Rectangular Patch Antenna with $90^{\circ}$ Slot on the Ground Plane}

The layout of the rectangular patch antenna with 90 degree slot on ground plane is shown in figure 2.3.1 with table 5 specification, While its simulated return loss as a function of frequency is shown in figure 2.3.2.

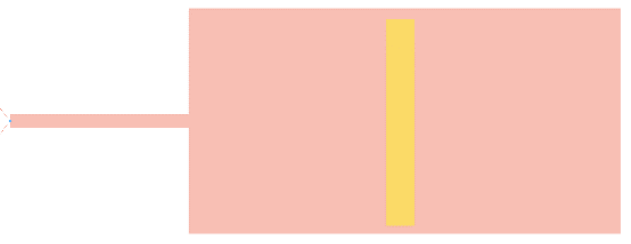

Figure 2.3.1 Rectangular patch antenna with rectangular slot made on the ground plane with $90^{\circ}$ to the antenna feed line

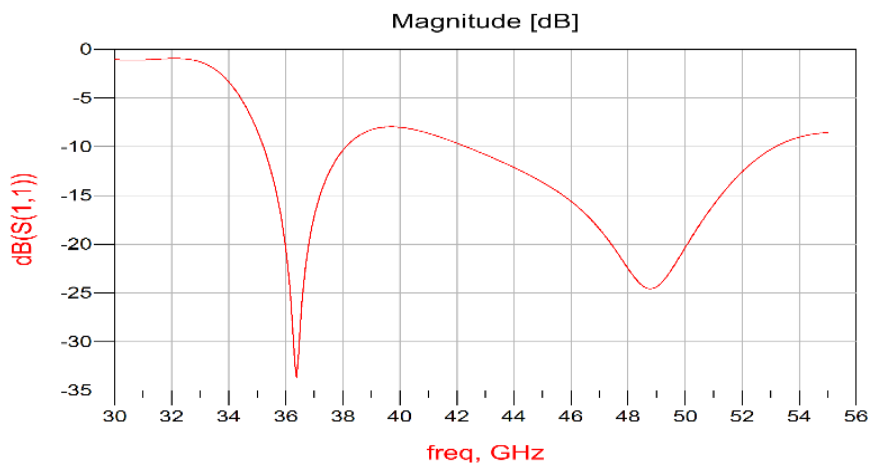

Figure 2.3.2. The return loss of the rectangular patch antenna with rectangular slot made on the ground plane with $90^{\circ}$ to the antenna feed line

It is observed from figure 2.3.2 that the proposed antenna operates at dual frequency $36.5 \mathrm{GHz}$ and 48.8 $\mathrm{GHz}$ with return less of $-33.6 \mathrm{~dB}$ and -24.54 respectively. High gain of $9.44 \mathrm{~dB}$ and $7.71 \mathrm{~dB}$ have been achieved respectively.The achieved bandwidths are 2.9 and $11.33 \mathrm{GHz}$ at frequency of 36.8 and 48.8 $\mathrm{GHz}$ respectively broad band operations have been obtained.

This proposed patch antenna generates a circular polarized performance as can be seen from figure 2.3.3, but unfortunately the lower radiation part cover small area, while the top one provides wide coverage area. A gain of $9.44 \mathrm{~dB}$ has been achieved as can be seen from table 8

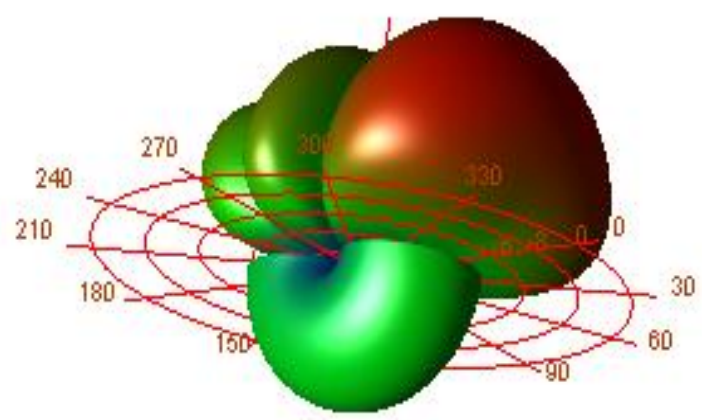

Figure 2.3.3. 3D Radiation pattern of the rectangular patch antenna with rectangular slot made on the ground plane with $90^{\circ}$ to the antenna feed line 
TABLE 8 The Rectangular Patch Antenna Parameters with Rectangular Slot Made on the Ground Plane With $90^{\circ}$ to the Antenna Feed Line Slot

\begin{tabular}{|c|c|c|}
\hline 11. Antenna Parameters & & В $\times 3$ \\
\hline Power radiated (Watts) & & 0.00176875 \\
\hline Effective angle (Steradians) & & 0.976631 \\
\hline Directivity (dBi) & & 11.0948 \\
\hline Gain (dBi) & & 9.4407 \\
\hline Maximim intensity (Watts/Steradian) & & 0.00181108 \\
\hline Angle of $U$ Max (theta, phi) & 48 & 0 \\
\hline $\mathrm{E}$ (theta) max (mag,phase) & 1.16815 & 176.561 \\
\hline E(phi) max (mag,phase) & 0.00118186 & 169.179 \\
\hline$E(x) \max$ (mag,phase) & 0.781644 & 176.561 \\
\hline$E(y) \max$ (mag,phase) & 0.00118186 & 169.179 \\
\hline$E(z) \max$ (mag,phase) & 0.868104 & -3.43912 \\
\hline OK & & \\
\hline
\end{tabular}

TABLE 9 Comparison of Performance Parameters of the Rectangular Patch with Slot on the ground Plane Geometries

\begin{tabular}{|c|c|c|c|c|c|c|}
\hline $\begin{array}{c}\text { Rectangular } \\
\text { patch antenna }\end{array}$ & $\begin{array}{c}\text { Polarizatio } \\
\mathbf{n}\end{array}$ & $\begin{array}{c}\text { (S11<-10dB) } \\
\text { BW GHz }\end{array}$ & $\begin{array}{c}\text { Return } \\
\text { Loss (dB) }\end{array}$ & $\begin{array}{c}\text { Gain } \\
\mathrm{dB}\end{array}$ & $\begin{array}{c}\text { Directivi } \\
\text { ty dB }\end{array}$ & $\begin{array}{c}\text { Remar } \\
\mathbf{k}\end{array}$ \\
\hline with $0^{\circ}$ slot & Linear & 13.38 & -46.72 & 9.3 & 11.39 & $\begin{array}{c}\text { Dual } \\
\text { Bandwidt } \\
\mathrm{h}\end{array}$ \\
\hline with $45^{\circ}$ slot & Circular & 14.06 & -42.35 & 9.51 & 11.24 & $\begin{array}{c}\text { Dual } \\
\text { Bandwidt } \\
\mathrm{h}\end{array}$ \\
\hline with $90^{\circ}$ slot & Circular & 14.26 & -33.68 & 9.44 & 11.11 & $\begin{array}{c}\text { Dual } \\
\text { Bandwidt } \\
\mathrm{h}\end{array}$ \\
\hline
\end{tabular}

From previous section with slot only on the top plane we obtained linear polarization in rectangular patch antenna. After adding rectangular slot in the ground plan with $45^{\circ}$ or $90^{\circ}$ angle to the antenna feed line, we obtained circular polarization with very wide bandwidth around $11.3 \mathrm{GHz}$ and there is some improvement observed in the return loss, gain and directivity. Furthermore, we got dual bandwidth at $45^{\circ}$ and $90^{\circ}$ slot angle which can be utilized in different frequency bands applications such as in satellite communication and millimeter wave communications systems.

\section{Circular Polarized Rectangular Patch Antenna with two types of Slots}

Another circular polarized rectangular patch antennas with insets feed and two types of slots have been designed and simulated as shown in next figures in order to study the effect of slot on the ground plane and on the top patch conductor of patch on the rectangular patch antenna performance The performances on the bandwidth, $\mathrm{S}$ parameter, gain, directivity and 3D radiation pattern have been investigated and compared between designs based on slot types and locations. 


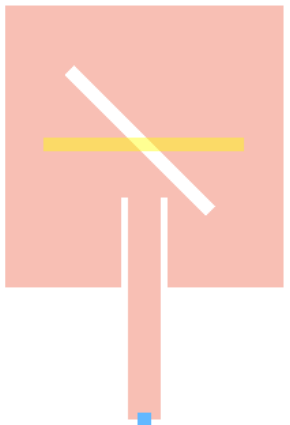

Type 1

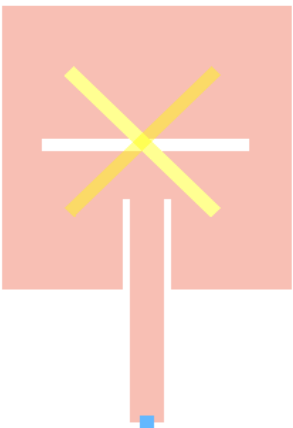

Type 3

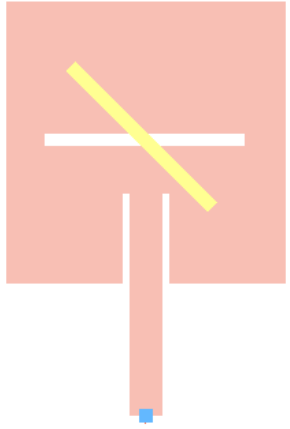

Type 2

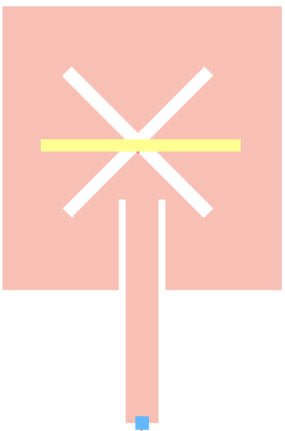

Type 4

Figure 3.1 The inset feed rectangular patch antenna with two types of slots

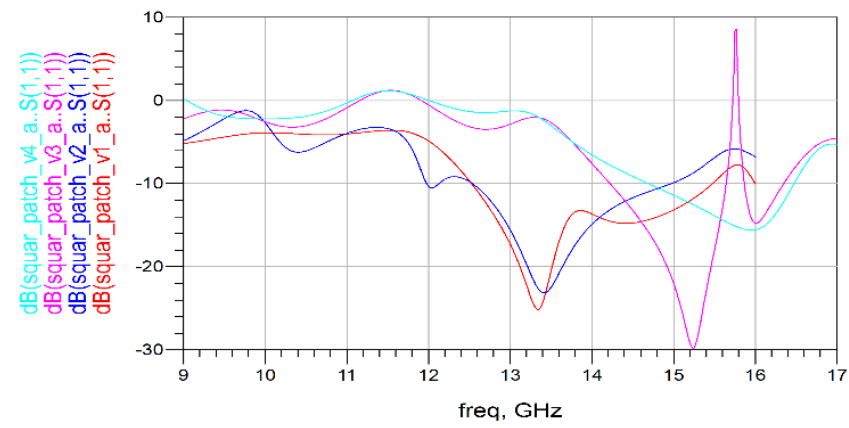

Figure 3.2 Frequency response of inset feed rectangular patch with two types of slots

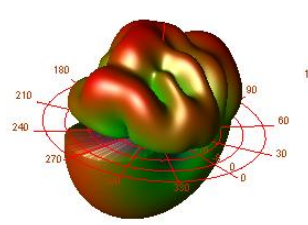

Type 1

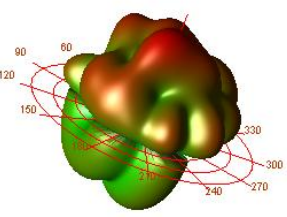

Type 2

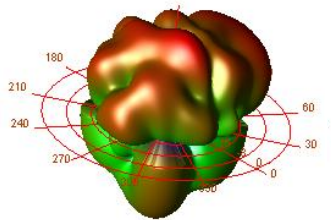

Type 3

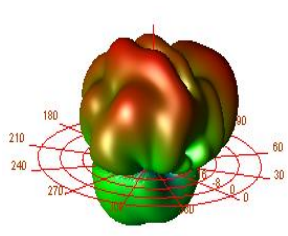

Type 4 
Figure 3.3. 3D Radiation pattern of inset feed rectangular patch antenna with two types of slots

Table 9 Antenna parameters of Inset Feed Rectangular Patch Antenna with Two Types of Slots

\begin{tabular}{|c|c|c|}
\hline (11) Antenna Parameters & & $8 \times$ \\
\hline Power radiated (Watts) & & 0.00609103 \\
\hline Effective angle (Steradians) & & 1.98617 \\
\hline Directivity (dBi) & & 8.01194 \\
\hline Gain (dBi) & & 7.63156 \\
\hline Maximim intensity (Watts/Steradian) & & 0.00306673 \\
\hline Angle of $U$ Max (theta, phi) & 41 & 91 \\
\hline $\mathrm{E}$ (theta) max (mag,phase) & 1.47627 & 121.725 \\
\hline E(phi) max (mag,phase) & 0.362326 & -35.0064 \\
\hline$E(x) \max ($ mag,phase) & 0.344494 & 146.271 \\
\hline$E(y) \max ($ mag,phase) & 1.1198 & 121.853 \\
\hline $\mathrm{E}(\mathrm{z}) \max ($ mag,phase) & 0.968522 & -58.2753 \\
\hline OK & & \\
\hline
\end{tabular}

Type 1

\begin{tabular}{|c|c|c|}
\hline (11) Antenna Parameters & & $8 \Omega 3$ \\
\hline Power radiated (Watts) & & 0.00970368 \\
\hline Effective angle (Steradians) & & 1. 16849 \\
\hline Directivity(dBi) & & 10.3158 \\
\hline Gain (dBi) & & 9.00721 \\
\hline Maximim intensity (Watts/Steradian) & & 0.00830443 \\
\hline Angle of $U$ Max (theta, phi) & 17 & 186 \\
\hline E(theta) max (mag,phase) & 0.820876 & 20.3742 \\
\hline E(phi) max (mag,phase) & 2.36288 & -101.676 \\
\hline$E(x)$ max (mag,phase) & 0.935499 & -146.695 \\
\hline$E(y)$ max (mag,phase) & 2.30744 & 80.0511 \\
\hline$E(z)$ max (mag,phase) & 0.240001 & -159.626 \\
\hline OK & & \\
\hline
\end{tabular}

Type 2

\begin{tabular}{|c|c|c|}
\hline (11. Antenna Parameters & & 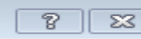 \\
\hline Power radiated (Watts) & & 0.0142052 \\
\hline Effective angle (Steradians) & & 1.44963 \\
\hline Directivity(dBi) & & 9.37953 \\
\hline Gain $(\mathrm{dBi})$ & & 8.41775 \\
\hline Maximim intensity (Watts/Steradian) & & 0.00979917 \\
\hline Angle of $U$ Max (theta, phi) & 20 & 330 \\
\hline$E$ (theta) max (mag,phase) & 1.69932 & -28.7785 \\
\hline E(phi) max (mag,phase) & 2.12028 & -138.886 \\
\hline$E(x) \max ($ mag,phase) & 1.42418 & -73.1264 \\
\hline$E(y) \max ($ mag,phase) & 2.23991 & -158.442 \\
\hline$E(z) \max ($ mag,phase) & 0.581202 & 151.222 \\
\hline OK & & \\
\hline
\end{tabular}




\section{Type 3}

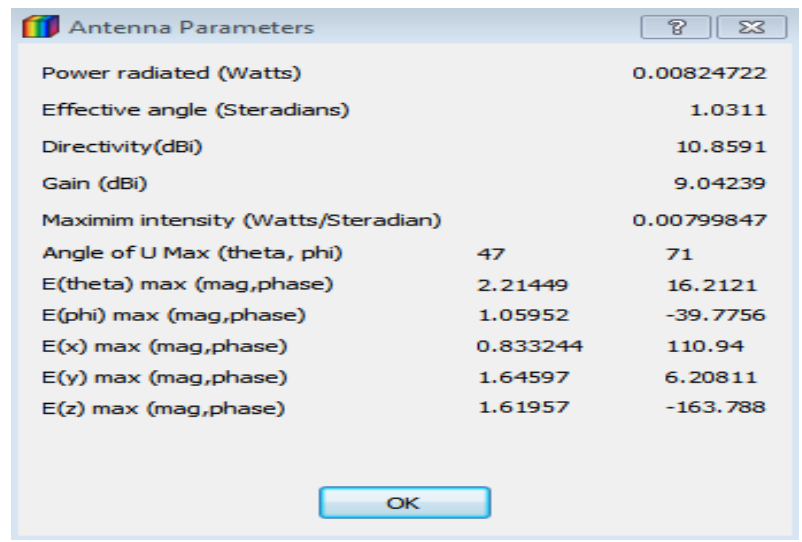

Type 4

TABLE 10. Comparison of Performance Parameters of Inset Feed Rectangular Patch Antenna with Two Types of Slots

\begin{tabular}{|c|c|c|c|c|c|}
\hline Antenna Type & $\begin{array}{c}\text { (S11 <-10dB) B W } \\
\text { GHz }\end{array}$ & $\begin{array}{c}\text { Return Loss } \\
(\mathbf{d B})\end{array}$ & $\begin{array}{c}\text { Gain } \\
\mathbf{d B}\end{array}$ & $\begin{array}{c}\text { Directivity } \\
\mathbf{d B}\end{array}$ & Remark \\
\hline TYPE 1 & 3 & -25.17 & 7.6 & 8 & \\
\hline TYPE 2 & 3 & -23.18 & 9 & 10.31 & \\
\hline $\begin{array}{c}\text { TYPE 3 } \\
\text { (Cross slots) }\end{array}$ & 1.93 & -29.75 & 8.41 & 9.37 & $\begin{array}{c}\text { Dual } \\
\text { Bandwidth }\end{array}$ \\
\hline $\begin{array}{c}\text { TYPE 4 } \\
\text { (Cross slots) }\end{array}$ & 1.78 & -15.62 & 9 & 10.85 & \\
\hline
\end{tabular}

From above summary table 10 , we can observed clearly that the slot type and location will effect on antenna performance. When the slot was on the ground plane with angle $0^{\circ}$ and the second slot on a patch conductor with angle $45^{\circ}$ we got bandwidth of $3 \mathrm{GHz}$ with high gain and directivity. On the other hand, the bandwidth decreases if the slot was cross but the gain and directivity were improved with cross slot. These designs can be utilized in Ku band applications such as satellite communication.

\section{Conclusion}

From the above study of the slot generated on different plane at different angles to the feed line it has been observed that the antenna performance is affected. One parameter enhances at the cost of another and vice versa. The paper would help choose the type needed for its application based on the performance of the antenna. The readers of the paper can also refer to paper by the authors published at different international journal on related topics[14,15,16,17,18,19].

\section{Acknowledegement}

The authors of the paper would like to acknowledge the Engineering Faculty in King AbdulAziz University (KAU), Saudi Arabia, for supporting the research. 


\section{References}

[1] C. Balanis "Antenna Theory Analysis and Design", second edition, John Wiley, 1997.

[2] R. Garg, P. Bhartia, I. Bahk, A. Ittipiboor, "Microstrip Antenna Design Handbook." Artech House, 2001.

[3] R. A. Sainati, "CAD of Microstrip Antennas for Wireless Antennas for Wireless Applications", Artech House, 1996.

[4] James, J.R., and P.S. Hall, " Handbook of Microstrip Antennas", Vol. 1, London: Peter Peregrines Ltd., 1989.

[5] Saunders, Simon R., “Antennas and Propagation for Wireless Communication Systems", John Wiley \& Sons Ltd., October 2003.

[6] Deschamps, G.A., "Microstrip microwave Antennas", Proc. 3rd USAF Symposium on Antennas, 1953.

[7] Munson, R.E., “ Single Slot Cavity Antennas Assembly”, US Patent No. 3713162. January 23, 1973.

[8] Newman, E.H., and Tulyathan, "Analysis of Microstrip Antennas Using Method of Moments," IEEE Trans. Antennas Propagation, Vol. AP-29, January 1981, pp.47-53.

[9] H.Pues and A Van de Capelle," Accurate transmission-line model for the rectangular microstrip antenna ," Proc. IEE, vol. 131, pt. H, no. 6, pp. 334-340, Dec. 1984.

[10] Jean-Francois Zurcher and Fred E.Gardiol, "Broadband Patch Antenna", Artech house,Boston,1995.

[11] Kin-Lu Wong,"Planar Antennas for Wireless Communications", Wiley- interscience,2005.

[12] Y.T.Lo and S.W.Lee, “Antenna Handbook Theory, Application and Design”, Van Nostrand Renhold Company, New York, 1988.

[13] Tso-Wei Li, Cheng-Liang Lai; Jwo-Shiun Sun, "Study of Dual-Band Circularly Polarized Microstrip Antenna", proceedings of the European Conference on Wireless Technology, 2005, pp. $79-80$.

[14] Adnan Affandi, Navin Kasim, and Mubashshir Husain, "Converging Algorithm for Calculation of Elements Current That Include Effects of Mutual Coupling," International Refereed Journal of Engineering and Science (IRJES) Volume 2, Issue 3 (March 2013), pp. 43-53

[15]Navin Kasim, Shankar. D, Mahesh. A, Dr. T. S. Rukmini, "Gain Enhancement of Microstrip Patch Antenna with Concave Dielectric Lens for Wireless Broadband Communication," on Microwaves, Antenna, Propogation and Remote Sensing, ICMARS- 2009, 19th - 21st December Jodhpur.

[16]. Adnan Affandi, Abdullah Dobaei, Navin Kasim "A Multi-Bands Circular Polarized of Series Triangular Microstrip Patch Antenna Array," Accepted To The 1st International Conference on Electrical Engineering and Applications (MIC-Electrical 2014)

[17]. Adnan Affandi, Abdullah Dobaei, Navin Kasim, "Rectangular Microstrip Patch Antenna Arrays 
with Inset for Cellular Phones Application), Accepted To The 1st International Conference on Electrical Engineering and Applications (MIC-Electrical 2014)

[18]. Adnan Affandi, Abdullah Dobaei, Navin Kasim, "A Multi-Bands Circular Polarized of Series Triangular Microstrip Patch Antenna Array), Accepted To The 1st International Conference on Electrical Engineering and Applications (MIC-Electrical 2014)

[19]. Adnan Affandi, Mubashshir Husain \& Navin Kasim, "Optimization for Spherical Phased Array Antenna," International Refereed Journal of Engineering and Science (IRJES), Volume 2, Issue 2 (February 2013), pp. 54-80. 